\section{Error in Interpreting Field Chlorophyll Fluorescence Measurements: Heat Gain from Solar Radiation}

\author{
Thomas E. Marler and Patrick D. Lawton \\ College of Agriculture and Life Sciences, University of Guam, UOG Station, \\ Mangilao, Guam 96923
}

Additional index words. heat stress, photochemical efficiency

\begin{abstract}
Temperature and chlorophyll fluorescence characteristics were determined on leaves of various horticultural species following a dark adaptation period where dark adaptation cuvettes were shielded from or exposed to solar radiation. In one study, temperature of Swietenia mahagoni (L.) Jacq. leaflets within cuvettes increased from $\approx 36 \mathrm{C}$ to $\approx 50 \mathrm{C}$ during a 30-minute exposure to solar radiation. Alternatively, when the leaflets and cuvettes were shielded from solar radiation, leaflet temperature declined to $33 \mathrm{C}$ in 10 to 15 minutes. In a second study, 16 horticultural species exhibited a lower variable : maximum fluorescence $\left(F_{v}: F_{m}\right)$ when cuvettes were exposed to solar radiation during the 30-minute dark adaptation than when cuvettes were shielded. In a third study with $S$. mahagoni, the influence of self-shielding the cuvettes by wrapping them with white tape, white paper, or aluminum foil on temperature and fluorescence was compared to exposing or shielding the entire leaflet and cuvette. All of the shielding methods reduced leaflet temperature and increased the $F_{v}: F_{m}$ ratio compared to leaving cuvettes exposed. These results indicate that heat stress from direct exposure to solar radiation is a potential source of error when interpreting chlorophyll fluorescence measurements on intact leaves. Methods for moderating or minimizing radiation interception during dark adaptation are recommended.
\end{abstract}

Many researchers measure chlorophyll fluorescence to study the transfer of electrons along photosynthetic systems because it provides a rapid method for determining the integrity of photosynthetic apparatus following exposure to environmental stresses (BolharNordenkampf et al., 1989; Krause and Weis, 1984). Illuminated leaves are continuously reemitting a small percentage of absorbed light energy as fluorescence. This continuous fluorescence provides little information in itself (Bolhar-Nordenkampf et al., 1989). Alternatively, useful information can be interpreted from fluorescence induction kinetics obtained from leaves on a dark-light transition; Papageorgiou (1975) describes the phases of this response in detail. Following illumination, fluorescence rises to an initial level $\left(\mathrm{F}_{0}\right)$, where photosystem-II reaction centers are fully open and most absorbed energy flows to photochemistry. Fluorescence increases from $\mathrm{F}_{0}$ to a maximum $\left(\mathrm{F}_{\mathrm{m}}\right)$, and the difference $\left(\mathrm{F}_{\mathrm{m}}-\right.$ $\left.\mathrm{F}_{0}\right)$ is termed variable fluorescence $\left(\mathrm{F}_{\mathrm{v}}\right)$. Variable fluorescence is an indication of the energy flowing to open reaction centers. The calculated $F_{v}: F_{m}$ ratio is proportional to a leaf's photochemical efficiency (DemmigAdams and Adams, 1992).

Received for publication 1 Feb. 1994. Accepted for publication 10 May 1994. Guam Agricultural Expt. Station Publication no. 173. The cost of publishing this paper was defrayed in part by the payment of page charges. Under postal regulations, this paper therefore must be hereby marked advertisement solely to indicate this fact.
Chlorophyll fluorescence instruments were originally designed for controlled laboratory conditions, although portable chlorophyll fluorescence instruments have been recently developed for field use. The required, dark adaptation period to measure fluorescence induction kinetics with field instruments has been obtained by various methods. For example, with the Brancker models (Richard Brancker Research, Ottawa, Canada), a leaf can be sandwiched between the metal sensing probe and a magnet, and the probe itself provides the dark adaptation. Alternatively, the Morgan CF-1000 (P.K. Morgan Instruments, Andover, Mass.) is designed with dark adaptation cuvettes that allow measuring without external light contamination of the leaf surface within the cuvettes.

These dark adaptation cuvettes are black. As a result, while they are mounted on leaves, they can gain substantial heat when the cuvettes are exposed to solar radiation. This heat then could be transferred by conduction to the lamina during the dark adaptation period. Because chlorophyll fluorescence is highly sensitive to high temperatures (e.g., Berry and Björkman, 1980) and is commonly used as the criterion for determining genotypic heat tolerance (e.g., Hetherington et al., 1983; Ruter, 1993), the magnitude of heat gain that can occur using these dark adaptation methods should be quantified. Our objective was to compare the temperature and chlorophyll fluorescence of the adaxial leaf surface within dark adaptation cuvettes exposed to or shielded from solar radiation. We used the Morgan CF1000 and accompanying cuvettes in our experiments.
Effects of shielding (Expt.1). The influence of exposing cuvettes to sunlight on leaf temperature was measured on leaflets of $S$. mahagoni from 1200 to $1500 \mathrm{HR}$ on 30 Oct. 1993. Conditions were mostly sunny, photosynthetic photon flux (PPF) was at 2250 to $2350 \mu \mathrm{mol} \cdot \mathrm{m}^{-2} \cdot \mathrm{s}^{-1}$, and air was at $33 \mathrm{C}$ during this experiment. Two cuvettes were placed on leaflets with similar orientation and exposure, and thermistors (PP Systems, Stotfield, U.K.) were positioned within each cuvette on the adaxial surface of the lamina. One cuvette of the pair was shielded from direct sunlight with opaque brown paper. Temperature was recorded every 1 to $3 \mathrm{~min}$ for the first $5 \mathrm{~min}$ and about every $5 \mathrm{~min}$ thereafter for $30 \mathrm{~min}$. This procedure was repeated for a total of four replications. In each case, before placing the cuvette, the leaf tissue had been fully exposed to sunlight since $\approx 0900 \mathrm{HR}$, assuring more than $3 \mathrm{~h}$ of high light exposure. Mean comparison of final leaf temperature was performed using a standard $t$ test.

Comparison of species (Expt. 2). We selected a range of horticultural crops to determine the influence of exposing or shielding cuvettes from solar radiation during dark adaptation on induced chlorophyll fluorescence. This survey of species included woody and herbaceous; $\mathrm{C}_{3}, \mathrm{C}_{4}$, and crassulacean acid metabolism; landscape, pomology, and olericulture; and monocotyledonous and dicotyledonous representatives (Table 1).

Measurements were obtained on mostly sunny days from 7 Oct. to 16 Nov. 1993. Leaves were selected from canopy areas that had received full-sun exposure throughout the day before positioning cuvettes. Measurements were confined to 1200 to $1400 \mathrm{HR}$ on each day, ensuring several hours of direct-sun exposure before measurement of chlorophyll fluorescence. A 30-min dark adaptation period preceded measuring fluorescence induction using excitation light with PPF of 700 $\mu \mathrm{mol} \cdot \mathrm{m}^{-2} \cdot \mathrm{s}^{-1}$. Eight measurements were made on each species, with four randomly selected cuvettes shielded from sunlight with opaque paper during the dark adaptation period. Mean comparison of fluorescence components was performed using a standard $t$ test. Data were analyzed separately for each species.

Self-shielding of cuvettes (Expt. 3). Cuvettes were prepared to provide self-shielding by applying several layers of white adhesive tape, wrapping with white paper, or wrapping with aluminum foil. The influence of these self-shielding methods on adaxial leaf temperature then was compared to exposing cuvettes to sunlight or shielding the lamina and cuvette with opaque paper, as previously described, providing a total of five treatments. Cuvettes were randomly placed on fully exposed leaflets of $S$. mahagoni beginning at 1200 HR on 31 Oct. 1993. Leaf temperature at the time the cuvettes were installed ranged from 35.0 to $35.5 \mathrm{C}$. Leaf temperature was recorded at 25-and 30-min intervals, and these two measurements were averaged to determine final leaf temperature. In each case, this 
procedure was repeated four times on leaflets that had been fully exposed to sunlight throughout the day. Leaf temperatures for the treatments were subjected to analysis of variance as a completely randomized design.

The influence of shielding treatments on induced chlorophyll fluorescence was determined on 13 and 16 Nov. 1993. Dark adaptation and fluorescence measurements were performed as previously described. There were four measurements on each day, for a total of eight replications. Fluorescence characteris-

Table 1. Chlorophyll fluorescence characteristics of horticultural crops as influenced by exposing or shielding cuvettes from solar radiation during a 30-min dark adaptation. Data were obtained during midday on mostly sunny days from 7 Oct. to 16 Nov. 1993.

\begin{tabular}{|c|c|c|c|c|}
\hline Species & Treatment & $\mathrm{F}_{0}$ & $\mathrm{~F}_{\mathrm{m}}$ & $\mathrm{F}_{\mathrm{v}}: \mathrm{F}_{\mathrm{m}}$ \\
\hline \multirow[t]{2}{*}{ Acacia auriculaeformis A. Cunn } & Exposed & 223 & 623 & 0.63 \\
\hline & Shielded & 270 & $1171^{*}$ & $0.76^{*}$ \\
\hline \multirow[t]{2}{*}{ Ananas comosus (L.) Merr. } & Exposed & 148 & 486 & 0.69 \\
\hline & Shielded & $82^{*}$ & 419 & $0.80^{*}$ \\
\hline \multirow[t]{2}{*}{ Annona muricata $\mathrm{L}$. } & Exposed & 318 & 672 & 0.51 \\
\hline & Shielded & 387 & $1065^{*}$ & $0.64^{*}$ \\
\hline \multirow[t]{2}{*}{ Averrhoa carambola $\mathrm{L}$. } & Exposed & 347 & 612 & 0.42 \\
\hline & Shielded & $244^{*}$ & $813^{*}$ & $0.70^{*}$ \\
\hline \multirow[t]{2}{*}{ Brassica oleracea L. } & Exposed & 223 & 854 & 0.73 \\
\hline & Shielded & 221 & $1249^{*}$ & $0.82^{*}$ \\
\hline \multirow[t]{2}{*}{ Carica papaya $\mathrm{L}$. } & Exposed & 175 & 361 & 0.52 \\
\hline & Shielded & $124^{*}$ & $481^{*}$ & $0.74^{*}$ \\
\hline \multirow[t]{2}{*}{ Cassia surattensis Burm. F. } & Exposed & 330 & 693 & 0.52 \\
\hline & Shielded & $253^{*}$ & 941 & $0.71^{*}$ \\
\hline \multirow[t]{2}{*}{ Cocos nucifera $\mathrm{L}$. } & Exposed & 265 & 607 & 0.57 \\
\hline & Shielded & 300 & $923^{*}$ & $0.68^{*}$ \\
\hline \multirow[t]{2}{*}{ Cucumis sativus $\mathrm{L}}$. & Exposed & 292 & 431 & 0.33 \\
\hline & Shielded & 343 & $755^{*}$ & $0.56^{*}$ \\
\hline \multirow[t]{2}{*}{ Hibiscus rosa-sinensis $\mathrm{L}$. } & Exposed & 174 & 486 & 0.64 \\
\hline & Shielded & 113 & 608 & $0.81^{*}$ \\
\hline \multirow[t]{2}{*}{ Litchi chinensis Sonn. } & Exposed & 253 & 482 & 0.48 \\
\hline & Shielded & 249 & $909^{*}$ & $0.72^{*}$ \\
\hline \multirow[t]{2}{*}{ Mangifera indica $\mathrm{L}$. } & Exposed & 229 & 367 & 0.36 \\
\hline & Shielded & 220 & $547^{*}$ & $0.59^{*}$ \\
\hline \multirow[t]{2}{*}{ Manilkara zapota Van Royan } & Exposed & 291 & 510 & 0.43 \\
\hline & Shielded & 213 & 611 & $0.65^{*}$ \\
\hline \multirow[t]{2}{*}{ Pandanus tectorius Sol. } & Exposed & 313 & 802 & 0.60 \\
\hline & Shielded & 388 & $1233^{*}$ & $0.69^{*}$ \\
\hline \multirow[t]{2}{*}{ Solanum melongena $\mathrm{L}$. } & Exposed & 491 & 796 & 0.36 \\
\hline & Shielded & 470 & $1195^{*}$ & $0.61^{*}$ \\
\hline \multirow[t]{2}{*}{ Zea mays L. } & Exposed & 504 & 1205 & 0.59 \\
\hline & Shielded & 426 & 1605 & $0.73^{*}$ \\
\hline
\end{tabular}

*Means within each species significant at $P \leq 0.05$ by $t$ test.

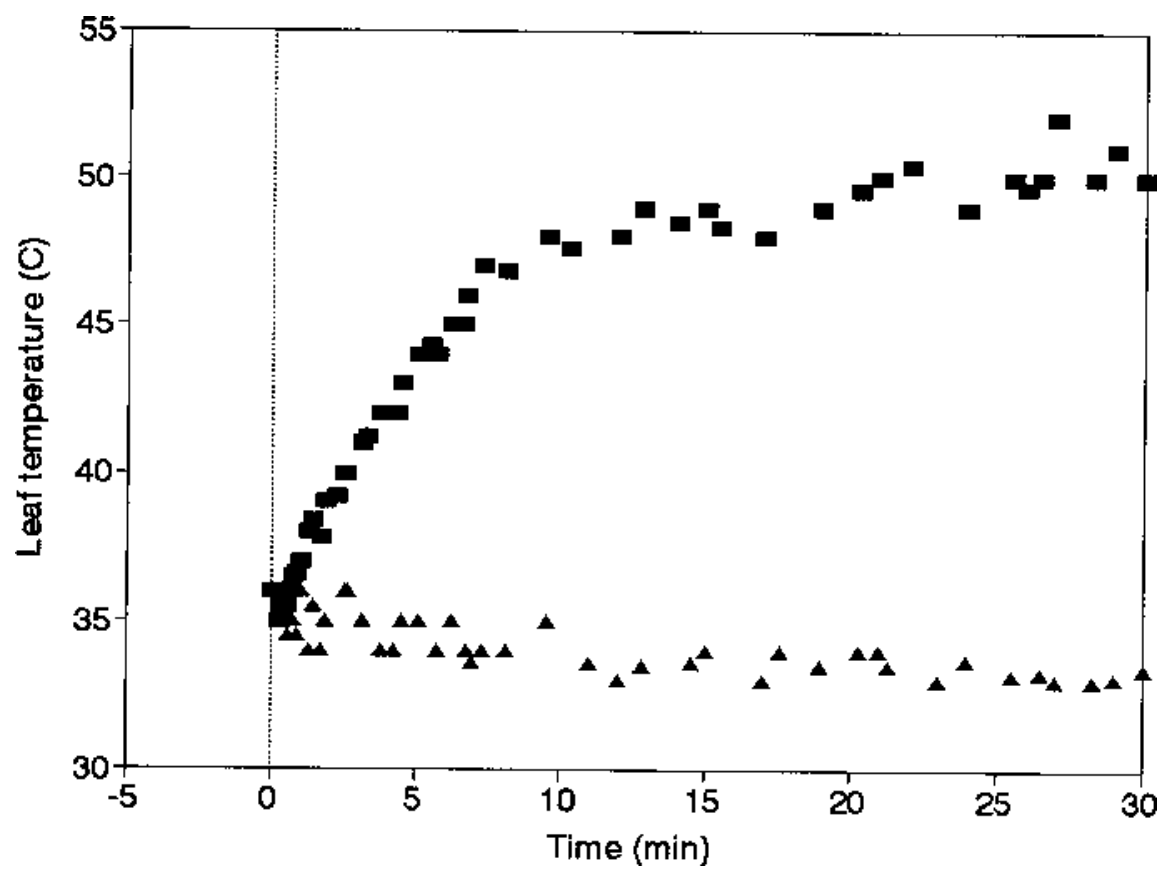

Fig. 1. Temperature of the adaxial surface of Swietenia mahagoni leaflets during 30 min within dark adaptation cuvettes that were exposed $(\boldsymbol{\square})$ or shielded $(\boldsymbol{A})$ from solar radiation. Each curve consists of pooled data points from four replications measured on 30 Oct. 1993.

tics for the treatments were subjected to analysis of variance as a randomized completeblock design, with measurement day defined as the block. Means were separated using Duncan's multiple range test when models were significant.

\section{Results and Discussion}

Experiment 1. Adaxial leaf temperature ranged from 35 to $36 \mathrm{C}$ at the time the cuvettes were positioned. The changes in leaf temperature over $30 \mathrm{~min}$ followed the same trend for each of the four replications; thus, the data were pooled. A rapid increase in temperature within cuvettes exposed to sunlight occurred in the first $10 \mathrm{~min}$, when temperature was $\approx 48 \mathrm{C}$ (Fig. 1). Thereafter, a more gradual rise in leaf temperature occurred until it reached $\approx 50 \mathrm{C}$ at $20 \mathrm{~min}$. Alternatively, leaf temperature within shielded cuvettes equilibrated with air temperature by 10 to 15 min after positioning the cuvettes (Fig. 1). Final leaf temperature within exposed cuvettes increased $(P \leq$ $0.01)$ over that within shielded cuvettes.

Experiment 2. For all species tested, the $\mathrm{F}_{\mathrm{v}}$ : $\mathrm{F}_{\mathrm{m}}$ ratio was lower $(P \leq 0.05)$ on leaves within cuvettes exposed to sunlight than within cuvettes shielded from sunlight (Table 1). This decline in the $\mathrm{F}_{\mathrm{v}}: \mathrm{F}_{\mathrm{m}}$ ratio for exposed cuvettes mostly was due to a decrease in $\mathrm{F}_{\mathrm{m}}(31 \%$ decrease on average). Four species exhibited a significant increase in $\mathrm{F}_{0}$. Ananas comosus was the only species in which a rise in $\mathrm{F}_{0}$ was solely responsible for the decline in the $F_{v}: F_{m}$ ratio. In several cases, a nonsignificant increase in $F_{0}$ and decrease in $F_{m}$ combined to produce the significant decrease in the $\mathrm{F}_{\mathrm{v}}: \mathrm{F}_{\mathrm{m}}$ ratio, due to their combined effect on $F_{v}$. Our results from leaves with cuvettes exposed to solar radiation are similar to the results of others, where a brief exposure to high temperature increased $\mathrm{F}_{0}$ or decreased $\mathrm{F}_{\mathrm{v}}, \mathrm{F}_{\mathrm{m}}$, the $\mathrm{F}_{\mathrm{v}}: \mathrm{F}_{\mathrm{m}}$ ratio, and the $\mathrm{F}_{\mathrm{v}}: \mathrm{F}_{0}$ ratio (Björkman and Powles, 1984; Björkman et al., 1980; Burke, 1990; Ludlow and Björkman, 1984; Ruter, 1993).

Experiment 3. All four methods for shielding cuvettes from sunlight reduced $(P \leq 0.01)$ radiant heat gain compared to exposed cuvettes (Table 2). None of the methods of selfshielding maintained temperature as low as providing a shield of opaque paper above the leaf and cuvette. The leaflets within cuvettes covered with adhesive tape were 2 to $3 \mathrm{C}$ hotter than leaflets within cuvettes wrapped in white paper or aluminum foil. Conductive heat transfer may have been minimized in the wrapped cuvettes due to the space between the cuvettes and the wrapping materials.

Differences in $\mathrm{F}_{0}, \mathrm{~F}_{\mathrm{m}}$, and the $\mathrm{F}_{\mathrm{v}}: \mathrm{F}_{\mathrm{m}}$ ratio occurred among shading treatments $(P \leq 0.01)$ and measurement days $(P \leq 0.01)$. Both experimental days were mostly sunny; however, brief interruptions in solar radiation by clouds occurred more often on $16 \mathrm{Nov}$. As a result, the $F_{v}: F_{m}$ ratio was higher on 16 Nov. than on 13 Nov. (data not shown), even though the influence of shading treatments on fluorescence followed the same pattern on both days. Leaflets within cuvettes exposed to sunlight had 
Table 2. Adaxial leaf temperature following $30 \mathrm{~min}$ within dark-adaptation cuvettes (31 Oct. 1993, n $=4)$ and fluorescence characteristics (13 and 16 Nov. 1993, n=8) of Swietenia mahagoni leaflets as influenced by exposing cuvettes to solar radiation or shielding cuvettes from solar radiation using various methods.

\begin{tabular}{lcccc}
\hline \hline Treatment & Temp & $\mathrm{F}_{0}$ & $\mathrm{~F}_{\mathrm{m}}$ & $\mathrm{F}_{\mathrm{v}}: \mathrm{F}_{\mathrm{m}}$ \\
\hline $\begin{array}{l}\text { Exposed } \\
\text { White adhesive }\end{array}$ & $49.5 \mathrm{a}^{\mathrm{z}}$ & $439 \mathrm{a}$ & $824 \mathrm{c}$ & $0.45 \mathrm{a}$ \\
$\quad$ tape & $39.5 \mathrm{~b}$ & $371 \mathrm{a}$ & $903 \mathrm{~b}$ & $0.59 \mathrm{~b}$ \\
$\begin{array}{c}\text { White paper } \\
\text { wrapping }\end{array}$ & $36.4 \mathrm{c}$ & $332 \mathrm{~b}$ & $966 \mathrm{~b}$ & $0.66 \mathrm{~b}$ \\
$\begin{array}{c}\text { Aluminum foil } \\
\text { wrapping }\end{array}$ & $37.5 \mathrm{c}$ & $394 \mathrm{a}$ & $1048 \mathrm{ab}$ & $0.63 \mathrm{~b}$ \\
$\begin{array}{c}\text { Shielding leaf } \\
\text { and cuvette }\end{array}$ & $33.6 \mathrm{~d}$ & $398 \mathrm{a}$ & $1150 \mathrm{a}$ & $0.66 \mathrm{~b}$ \\
\hline
\end{tabular}

${ }^{\mathrm{z}}$ Mean separation within columns according to Duncan's multiple range test at $P \leq 0.01$.

lower $F_{v}: F_{m}$ ratio than all of the methods of shielding solar radiation (Table 2). However, no differences in the $\mathrm{F}_{\mathrm{v}}: \mathrm{F}_{\mathrm{m}}$ ratio existed among the four methods of shielding. A similar reduction in $\mathrm{F}_{\mathrm{m}}$ occurred in leaflets exposed to solar radiation when compared to leaflets shielded from sunlight. Leaflets within cuvettes wrapped with white paper had lower $\mathrm{F}_{0}$ than that of the other three shielding treatments.

Until portable instruments allowed fluorescence measurement under field conditions, the potential for heat gain due to solar radiation during dark adaptation was not a factor. These data indicate that heat stress is a potential complication when using the described dark adaptation methods with portable fluorescence instruments in the field. An inadvertent increase in temperature within the cuvettes may artificially inflate any true decline in the $F_{v}: F_{m}$ ratio resulting from a period of exces- sive light exposure (before positioning cuvettes). A greater degree of reduction in photochemical efficiency (based on the $\mathrm{F}_{\mathrm{v}}: \mathrm{F}_{\mathrm{m}}$ ratio) than is actually true may be interpreted and reported. Overestimation of the reduction in photochemical efficiency would depend on genotypic tolerance to heat stress and environmental conditions that affect the amount of heat gain during measurements.

Another possible result of heat gain during dark adaptation may be direct heat injury to tissue within cuvettes, depending on the duration of exposure to the higher temperatures. For example, direct heat injury of hollies (Ilex spp.) (Ruter, 1993) and Citrus (Ahrens and Ingram, 1988) leaves was reported at $\approx 52$ to $54 \mathrm{C}$, which is close to the temperature range that we measured within exposed cuvettes. If direct heat injury could occur when measuring fluorescence on heat-sensitive species, these measurements could not be considered nondestructive and noninvasive, as is commonly assumed (Bolhar-Nordenkampf et al., 1989).

The possibility for error in experimental interpretation should be recognized when using field instruments to obtain induced chlorophyll fluorescence following a dark adaptation period. Some form of moderating or minimizing radiation interception during dark adaptation is recommended. At least, the orientation and exposure to sunlight during dark adaptation should be standardized throughout all cuvettes within a study, and any report generated from that study should include a description of those experimental conditions.

\section{Literature Cited}

Ahrens, M.J. and D.L. Ingram. 1988. Heat tolerance of citrus leaves. HortScience 23:747-748.

Berry, J.A. and O. Björkman. 1980. Photosynthetic response and adaptation to temperature in higher plants. Annu. Rev. Plant Physiol. 31:491-543.

Björkman, O., M.R. Badger, and P.A. Armond. 1980. Response and adaptation of photosynthesis to high temperatures, p. 233-249. In: N.C. Turner and P.J. Kramer (eds.). Adaptation of plants to water and high temperature stress. Wiley, New York.

Björkman, O. and S.B. Powles. 1984. Inhibition of photosynthetic reactions under water stress: Interaction with light level. Planta 161:490-504.

Bolhar-Nordenkampf, H.F., S.P. Long, N.R. Baker, G. Oquist, U. Schreiber, and E.G. Lechner. 1989. Chlorophyll fluorescence as a probe of the photosynthetic competence of leaves in the field: A review of current instrumentation. Functional Ecol. 3:497-514.

Burke, J.J. 1990. Variation among species in the temperature dependence of the reappearance of variable fluorescence following illumination. Plant Physiol. 93:652-656.

Demmig-Adams, B. and W.W. Adams, III. 1992. Photoprotection and other responses of plants to high light stress. Annu. Rev. Plant Physiol. Plant Mol. Biol. 43:599-626.

Hetherington, S.E., R.M. Smillie, P. Malagamba, and Z. Huaman. 1983. Heat tolerance and cold tolerance of cultivated potatoes measured by the chlorophyll-fluorescence method. Planta 159:119-124.

Krause, G.H. and E. Weis. 1984. Chlorophyll fluorescence as a tool in plant physiology. II. Interpretation of fluorescence signals. Photosyn. Res. 5:139-157.

Ludlow, M.M. and O. Björkman. 1984. Paraheliotropic leaf movement in Siratro as a protective mechanism against drought-induced damage to primary photosynthetic reactions: Damage by excessive light and heat. Planta 161:505-518.

Papageorgiou, G. 1975. Chlorophyll fluorescence. An intrinsic probe of photosynthesis, p. 320 366. In: J. Amesz Govindjee (ed.). Bioenergetics of photosynthesis. Academic, New York.

Ruter, J.M. 1993. Foliar heat tolerance of two hybrid hollies. HortScience 28:650-652. 